\title{
Preface to the Special Issue on Commemorating the Centenary of Duzheng YE's Birth
}

\author{
Jiang ZHU \\ Institute of Atmospheric Physics, Chinese Academy of Sciences, Beijing 100029, China
}

Citation: Zhu, J., 2017: Preface to the Special Issue on Commemorating the Centenary of Duzheng YE's Birth. Adv. Atmos. Sci., 34(10), 1035, doi: 10.1007/s00376-017-7002-9.

Prof. Duzheng YE (also spelt Tu-Cheng Yeh) was one of the main founders of modern meteorology in China. He devoted himself to the Earth sciences for more than 70 years, during which time his contributions, to name just a few, included establishing Tibetan Plateau meteorology; developing the theory of atmospheric longwave energy dispersion, and therefore providing the theoretical basis for modern weather forecasting; and expanding global change research by building a framework of "orderly human adaptation" in the context of a life-supporting environment and proposing climate change adaptation theories. He actively participated in, and advised for, the development of meteorological operational systems in China, and made outstanding contributions to modern meteorological operations in the country. He also served as an executive member of many international organizations, and he was awarded the 48th IMO (International Meteorological Organization) Prize in 2003 and the Highest Science and Technology Awards of China in 2005.

With great sadness, and considerable loss to the meteorological community, Professor YE passed away on 16 October 2013, at the age of 98. To commemorate his life's achievements, the Institute of Atmospheric Physics, where he had worked since returning to China in 1948, organized the "Duzheng YE Centenary Symposium: From General Circulation to Global Change" in 2016 in Nanjing, China. We invited his friends, colleagues (including those who have grown to know him through his publications - not just in person) and former students (many of whom have become renowned scientists themselves) to review his contributions to, and inspiration within, the fields of atmospheric science and global change. Following the symposium, invitations were extended to contribute to this special issue in Advances in Atmospheric Sciences (AAS), which we feel is particularly fitting given Professor YE was also the founding Editor-in-Chief of this journal.

The special issue consists of five reviews and five original articles, each focusing on an aspect of Professor YE's achievements, and the latest developments based on or inspired by his theories. The special issue is just one manifestation of how widely Professor YE is remembered and respected and, as the current Co-Editor-in-Chief of AAS, I thank all the authors for travelling from far and wide to the symposium and devoting their time to writing for this special issue. 